\title{
Preparation of Catalysts from Renewable and Waste Materials
}

\author{
Daniele Dondi *(D) and Dhanalakshmi Vadivel \\ Department of Chemistry, University of Pavia, via Taramelli 12, 27100 Pavia, Italy; \\ dhanalakshmi.vadivel@unipv.it \\ * Correspondence: daniele.dondi@unipv.it
}

Received: 25 May 2020; Accepted: 5 June 2020; Published: 12 June 2020

Research in the field of renewable, non-polluting energy sources is a current trend because of the need to replace fossil fuels due to socioeconomic issues and pollution by carbon-oxygen derivatives. If the replacement is done by using derivatives from waste materials (such as industrial or small-scale production) to prepare new catalysts, pollution reduction is more desirable. As seen in this Special Issue, heat treatment is among the most common initial procedures for the preparation of catalysts as it can reduce the complexity and variability of the starting material.

While speaking about pollution, water pollution is an important topic from both a flora and fauna perspective. Inhibition and destruction of pollutants like organic dyes and antibiotics in water is an emerging field, since the wastewater coming from dye industries and farms is difficult to treat.

In the research paper "Utilization of Coal Fly Ash and Rice Hull Ash as Geo-polymer Matrix-cum-Metal Dopant Applied to Visible-Light-Active Nano titania Photocatalyst System for Degradation of Dye in Wastewater", a geo-polymer with nanopores made from coal fly and rice hull ash was used as the supportive matrix for $\mathrm{a} \mathrm{TiO}_{2}$ photocatalyst. The suspension/solidification method gives a visible-light-active photocatalyst for methylene blue degradation. The described method leads to the surface activation of $\mathrm{TiO}_{2}$ photocatalyst by nanoporous morphological geo-polymers. It is really a wonderful path to make a photocatalyst from cost-effective materials like ash by forming geo-polymers [1].

In the paper "Efficient Heterogeneous Activation of Persulfate by Iron-Modified Biochar for Removal of Antibiotic from Aqueous Solution: A Case Study of Tetracycline Removal", the authors show a method for tetracycline removal from water. Nowadays, water pollution is a big deal, and removal of antibiotics is a significant topic. Here, a functionalized biochar is produced starting from coffee grounds and magnetite by a higher temperature process. The material produced can remove and abate tetracycline efficiently in the presence of persulfate. Many parameters such as $\mathrm{pH}$, amount of biochar, sodium persulfate and tetracycline concentrations were studied to enhance pollutant degradation and removal. The highest removal of tetracycline, around $96 \%$, is achieved at pH2 with $1 \mathrm{mM}$ tetracycline concentration [2].

In the research paper "Sustainable Biodiesel Synthesis from Honne-Rubber-Neem Oil Blend with a Novel Mesoporous Base Catalyst Synthesized from a Mixture of Three Agro wastes", a solid catalyst is synthesized starting from three different ashes with different mesoporous structures. A catalyst consisting of nanosized materials was found to be useful for synthesizing a biodiesel, which can be a substitute of fossil fuel. In the optimal conditions, the catalyst was found, produced from cocoa pod husk, plantain peel and kola nut pod husk ashes (CPK), at a concentration of $1.158 \mathrm{wt} \%$ in MeOH:oil 12:1 mixture, which produced the highest yield of transesterification when it was submitted to microwave irradiation for $6 \mathrm{~min}$. The synthesis technique is very simple. The reaction is also very quick and requires less than 10 min of microwave irradiation. This method might be useful for the need of substituted fuel in the near future [3]. 
In the research paper "Palm Biochar-Based Sulphated Zirconium (Zr-AC-HSO ${ }_{3}$ ) Catalyst for Methyl Ester Production from Palm Fatty Acid Distillate", a waste biomass (derived from palm) is converted into activated carbon. The sulphated zirconium-doped activated catalyst obtained is characterized by many techniques. The catalyst is useful for the esterification of fatty acids into fatty acid methyl ester with higher yields. The significant fuel features are also verified. This paper is interesting also because biomasses from palm are used both for the catalyst preparation and as a substrate for biodiesel production. At optimal conditions of $3 \mathrm{wt} \%$ of catalyst at $75{ }^{\circ} \mathrm{C}$ for $3 \mathrm{~h}$ in methanol, a palm fatty acid distillate (PFAD) molar ratio of $15: 1$ yields $94.3 \%$ of fatty acid methyl ester (FAME) [4].

In "Esterification of Palm Fatty Acid Distillate for Biodiesel Production Catalyzed by Synthesized Kenaf Seed Cake-Based Sulfonated Catalyst", a sulfonated kenaf seed cake (KSC) catalyst with high porosity and specific surface area is produced by adding phosphoric acid. The obtained material is used as a catalyst to produce methyl ester fuel from palm fatty acid distillate (PFAD) in high yields. The activated catalyst was characterized by many techniques. The $\mathrm{SO}_{3} \mathrm{H}-\mathrm{KSC}$ catalyst is amorphous in nature and possesses a high surface area. At the optimal conditions, a catalyst concentration of $2 \mathrm{wt} \%$ at $338 \mathrm{~K}$ for $90 \mathrm{~min}$ in methanol-PFAD molar ration of 10:1 yields $98.7 \%$ free fatty acid (FFA) conversion and $97.9 \%$ fatty acid methyl ester (FAME) was found [5].

In the research paper "Hydrothermally Carbonized Waste Biomass as Electrocatalyst Support for $\alpha-\mathrm{MnO}_{2}$ in Oxygen Reduction Reaction", the authors consider the preparation of an electrode for the electrochemical oxygen reduction reaction. A high durability and cost-effective electrocatalyst is prepared by supporting $\alpha-\mathrm{MnO}_{2}$ onto porous, amorphous carbon. The latter is produced by hydrothermal carbonization. The way of occupying oxygen sensitive functions by the catalyst is a new approach to block the oxidation of compounds and to perform an oxygen reduction reaction. The prepared material enhances the effect of $\alpha-\mathrm{MnO}_{2}$ catalyst. More in detail, carbon supported $\alpha-\mathrm{MnO}_{2}$ is synthesized by hydrothermal carbonization (HTC) at $250^{\circ} \mathrm{C}$ for $12 \mathrm{~h}$, providing the highest limiting current density and lower over potential during oxygen reduction reaction (ORR) [6].

This collection of scientific articles implies the importance of fossil fuel replacement and wastewater treatment by using a cost-effective waste material as catalysts, including applications in electrocatalysis. We sincerely thank all authors for their valuable contributions and the editorial team of Catalysts for their kind support. This Special Issue would possible only because of their harmonization.

Conflicts of Interest: The authors declare no conflict of interest.

\section{References}

1. Shimizu, E.; Promentilla, M.A.; Yu, D.E. Utilization of Coal Fly Ash and Rice Hull Ash as Geo-polymer Matrix-cum-Metal Dopant Applied to Visible-Light-Active Nano titania Photocatalyst System for Degradation of Dye in Wastewater. Catalysts 2020, 10, 240.

2. Nguyen, V.-T.; Hung, C.-M.; Nguyen, T.-B.; Chang, J.-H.; Wang, T.-H.; Wu, C.-H.; Lin, Y.-L.; Chen, C.-W.; Dong, C.-D. Efficient Heterogeneous Activation of Persulfate by Iron-Modified Biochar for Removal of Antibiotic from Aqueous Solution: A Case Study of Tetracycline Removal. Catalysts 2019, 9, 49.

3. Falowo, O.A.; Ojumu, T.V.; Pereao, O.; Betiku, E. Sustainable Biodiesel Synthesis from Honne-Rubber-Neem Oil Blend with a Novel Mesoporous Base Catalyst Synthesized from a Mixture of Three Agrowastes. Catalysts 2020, 10, 190.

4. Rashid, U.; Soroush, S.; Soltani, S.; Choong, T.S.Y.; Shean, T.; Nehdi, I.A.; Ahmad, J.; Ngamcharussrivichai, C. Palm Biochar-Based Sulphated Zirconium (Zr-AC-HSO3) Catalyst for Methyl Ester Production from Palm Fatty Acid Distillate. Catalysts 2019, 9, 1029. 
5. Akinfalabi, S.-I.; Rashid, U.; Shean, T.Y.C.; Nehdi, I.A.; Sbihi, H.M.; Gewik, M.M. Esterification of Palm Fatty Acid Distillate for Biodiesel Production Catalyzed by Synthesized Kenaf Seed Cake-Based Sulfonated. Catalysts 2019, 9, 482.

6. Panganoron, H.O.; Pascasio, J.D.A.; Esparcia, E.A., Jr.; del Rosario, J.A.D.; Ocon, J.D. Hydrothermally Carbonized Waste Biomass as Electrocatalyst Support for $\alpha-\mathrm{MnO} 2$ in Oxygen Reduction Reaction. Catalysts 2020, 10, 177.

(C) 2020 by the authors. Licensee MDPI, Basel, Switzerland. This article is an open access article distributed under the terms and conditions of the Creative Commons Attribution (CC BY) license (http://creativecommons.org/licenses/by/4.0/). 